\footnotetext{
1. FCPS (Pediatric Medicine)

Assistant Professor Pediatric Medicine

Nishtar Medical University Hospital

Multan.

2. FCPS (Pediatric Medicine)

Assistant Professor Pediatric Medicine

Nishtar Medical University Hospital,

Multan.

3. MBBS

Post Graduate Registrar Pediatric

Medicine

Nishtar Medical University Hospital,

Multan.

4. MBBS

Post Graduate Registrar of Pediatric

Medicine

Nishtar Medical University Hospital,

Multan.

5. MBBS

Post Graduate Registrar Pediatric

Medicine

Nishtar Medical University Hospital,

Multan.

6. MBBS

Post Graduate Registrar Pediatric

Medicine

Nishtar Medical University Hospital,

Multan
}

Correspondence Address:

Dr. M Faisal Mehar

Department of Pediatric Medicine

Nishtar Medical University Hospital, Multan.

drmfaisalmehr@yahoo.com

Article received on:

26/03/2020

Accepted for publication:

$24 / 07 / 2020$

\section{Frequency of hypertension among children having acute kidney injury (AKI) at A Tertiary Care Hospital.}

\begin{abstract}
M Faisal Mehar', Afsheen Asghar Khan², Rushan Hassan ${ }^{3}$, Madiha Naz ${ }^{4}$, Bushra Iqbal ${ }^{5}$,
\end{abstract} Ali Rehan Nasir 6

ABSTRACT... Objectives: To know the frequency of hypertension among children having acute kidney injury (AKI) at a tertiary care hospital. Study Design: Descriptive, cross-sectional study. Setting: Department of Pediatric Medicine, Nishtar Hospital, Multan, Period: 1st January to 31 December 2019. Material \& Methods: A total of 718 children with AKI were included from department of Pediatric medicine, Nishtar Hospital, Multan. Once registered, study variables were noted along with systolic and diastolic blood pressure. Results: Of these 718 study cases, majority, 439 (61.1\%) were male, $435(61.0 \%)$ belonged to rural areas, $443(61.7 \%)$ from poor socioeconomic status and 551 (76.7\%) mothers were illiterate. Mean age was 4.33 \pm 2.56 years whereas mean body mass index was $23.58 \pm 3.17 \mathrm{~kg} / \mathrm{m}^{2}$. Overall, family history of AKI was noted in 165 (23.0\%) children. Hypertension was noted in 228 (31.8\%) cases. Conclusion: Very high frequency of hypertension was seen in children presenting with AKI.

Key words: $\quad$ Acute Kidney Injury, Children, Hypertension.

Article Citation: Mehar MF, Khan AA, Hassan R, Naz M, Iqbal B, Nasir AR. Frequency of hypertension among children having acute kidney injury (AKI) at $A$ Tertiary Care Hospital. Professional Med J 2021; 28(1):47-51. https://doi.org/10.29309/TPMJ/2021.28.01.4678

\section{INTRODUCTION}

Acute kidney injury (AKI) is described as a reversible escalation in the blood concentration of creatinine and nitrogenous waste products and by the incompetence of the kidneys to adjust fluid and electrolyte homeostasis properly. ${ }^{1,2}$ The incidence as well as AKI related morbidity and mortality is increasing worldwide. ${ }^{3}$ In the recent years, a more standardized definition of the AKI has granted a more precise evaluation about the epidemiological aspects of AKI. ${ }^{4}$ Advancements in the last few decades have also helped a lot in real time stratification and prevention of AKI among children at the healthcare facilities. Emergence of modern verified clinical scores have also advanced our capacity to forecast AKI, providing us logical context for using biomarkers among hospitalized cases. ${ }^{5}$ New non-invasive tools helping diagnosis and predictive biomarkers are in use around the globe to assist our abilities to diagnose and predict outcomes and recover of $\mathrm{AKI}^{4}$
According to "Acute Kidney Injury Network" (AKIN), abrupt (within 48 hours) reduction in renal functions are described $a s^{6} 1$ ) absolute increase in serum creatinine $>0.3 \mathrm{mg} / \mathrm{dl}$ from baseline or ii) increase in serum creatinine $>50 \%(1.5$ fold from baseline) or iii) decline in urine output (oliguria $<0.5 \mathrm{ml} / \mathrm{kg} /$ hour for $>6$ hours). In majority of the patients, baseline creatinine is not available. AKI has been found to be non-oliguric or even polyuric among $10-15 \%$ of the patients that may be the cause of a missed diagnosis on clinical evaluation if clinician is relying on daily urine volume solely., ${ }^{4,7}$ Glomerulonephritis can also present among children having AKI and might progress to "rapid glomerulonephritis" (RPGN). Common clinical features of AKI are hypertension, oedema, hematuria (frequently gross), and a rapid rise in blood urea nitrogen and creatinine levels. ${ }^{8}$ TresaV et $\mathrm{al}^{9}$ reported $37.1 \%$ of the children with AKI to have hypertension.

This study was done to determine the frequency 
of hypertension among children having $\mathrm{AKI}$ at a tertiary care hospital. As there is no such study done in our local population on this topic, the results of our study were thought to report useful baseline data of our local population which will be compared with that of being reported from different parts of the world. This work will also help clinicians to anticipate morbidities like hypertension and treat them early to avoid further complications.

\section{MATERIAL \& METHODS}

This descriptive, cross-sectional study was done at the Department of Pediatric Medicine, Nishtar Hospital, Multan, from $1^{\text {st }}$ January to 31 December 2019. Approval from "Institutional Ethical \& Research Committee" was taken. Informed consent was sought from parents/guardians of all study participants.

A total of 718 children of both gender with AKI and aged less than 12 years were enrolled during the study duration. AKI was labeled as an abrupt (within 48 hours) reduction in kidney function defined by absolute increase in serum creatinine equal or more than $0.3 \mathrm{mg} / \mathrm{dl}$ and decreased urine output. Children as known cases of chronic kidney disease (CKD) on hemodialysis, or having chronic obstructive pulmonary disease, congenital heart diseases, metabolic disorders and those having malignancies, or having cerebral palsy, febrile seizures or epilepsy were excluded. Systolic and diastolic blood pressure (BP) was measured and noted in all the patients. Hypertension was documented. Hypertension was diagnosed if a child's BP was $>95^{\text {th }}$ percentile for height, age and gender, two different occasions 24 hours apart.

SPSS version 20.0 was used for data analysis. Mean and standard deviation calculated for age and body mass index (BMI) while frequencies and percentage for gender, age groups, residential status, educational status of mother and hypertension. Effect modifiers like age of patients, gender of patient, educational level of mothers and residential status were controlled by making stratified tables. Post stratification chisquare test was applied considering $P$ value $<$
0.05 as significant.

\section{RESULTS}

Out of a total of 718 study cases, 439 (61.1\%) were male and 279 (38.9\%) female. Overall mean age was $4.33 \pm 2.56$ years (ranging 1 to 11 years). Mean age among male and female cases were $4.55 \pm 2.86$ and $3.99 \pm 1.97$ years respectively $(p=0.045)$. Most cases, $553(74.2 \%)$ were less than 5 years of age, 435 (60.6\%) belonged to rural areas and $443(61.7 \%)$ had poor socioeconomic status. A total of $551(76.7 \%)$ mothers of patients were illiterate whereas family history of AKI noted in 165 (23.0\%). Overall mean BMl was 23.58 $\pm 3.17 \mathrm{~kg} / \mathrm{m}^{2}$ and obesity was present in 129 $(18.0 \%)$ of our study cases.

Figure-1 shows that hypertension was noted in $228(31.8 \%)$ of our study cases.

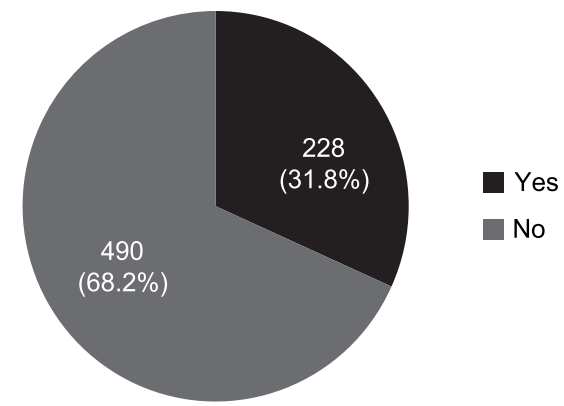

Figure-1. Frequency of hypertension among study cases $(n=718)$

Hypertension was stratified with regards to gender, age, residential status, family history of hypertension, obesity, level of maternal education and obesity (Table-I). Male gender, age less than 5 years, socioeconomic status as poor, family history of hypertension and obesity were found significantly associated with the presence of hypertension.

\section{DISCUSSION}

The incidence of $\mathrm{AKI}$ is rising while the etiological aspects of AKI have shifted from a primary kidney disease to multifactorial causes., ${ }^{4,10}$ In developed countries, standard definitions of AKI has provided better understanding of epidemiology as well as outcomes related to pediatric population involved. ${ }^{11,12}$ 


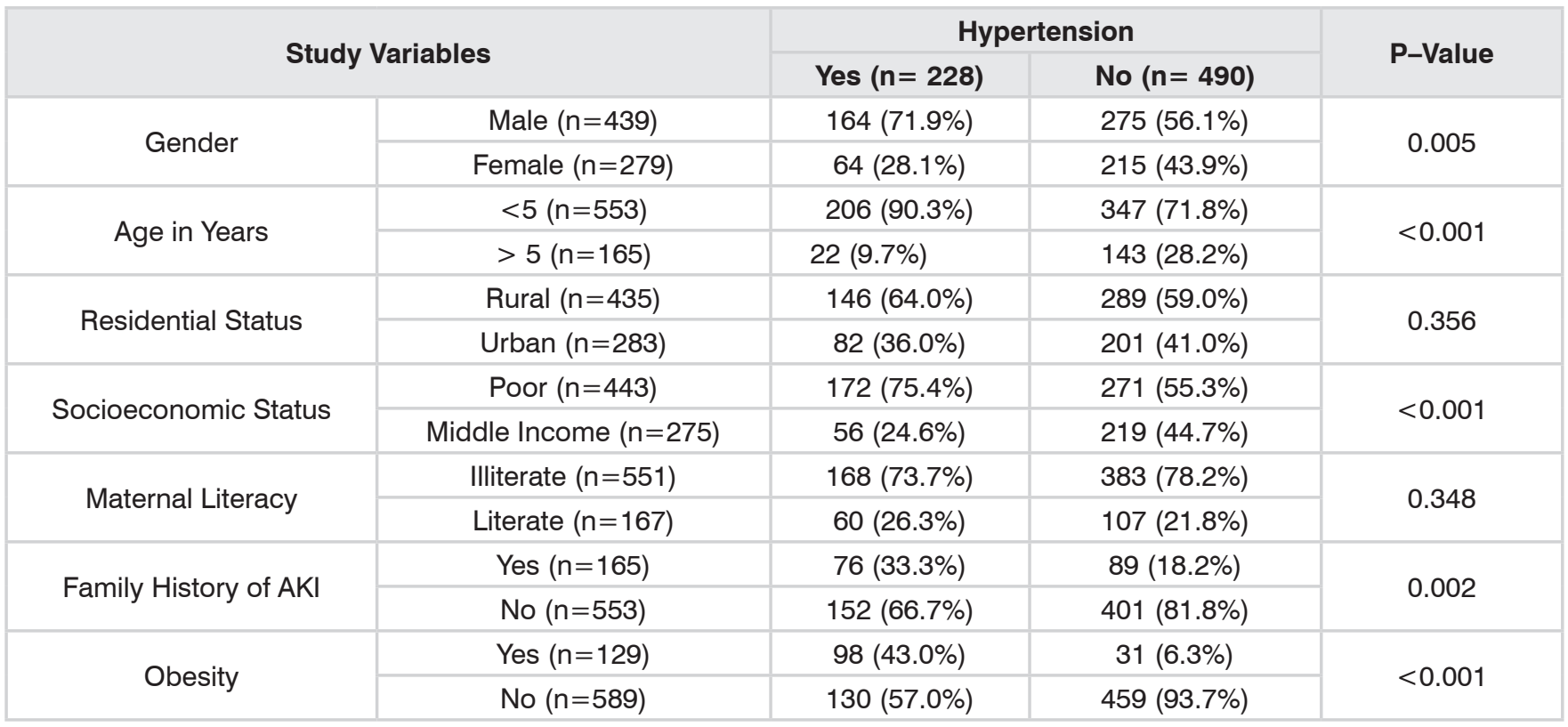

On the other hand, in developing countries, limited data is available about the epidemiology and factors affecting the outcome of AKI among children. ${ }^{13,14}$ Presence of AKI is high among critically ill children. ${ }^{15}$ Recent data suggest that $\mathrm{AKI}$ is found among $5 \%$ and $27 \%$ of non-critically and critically ill pediatric cases, respectively. ${ }^{16}$ To make the scenario worse, AKI as well as fluid overload are independently linked with worse outcomes like mortality.

Diagnosis of $\mathrm{AKI}$ is dependent upon urine output and creatinine measurement which is challenging to note among children. However, discovery of novel biomarkers and modern risk stratification tools are leading us to advanced detection and diagnostic approaches. As we known, no exact treatments is endorsed, strategies aiming towards prevention of AKI are a subject of discussion while more and more evidence suggests that detecting AKI early can lead to improved outcomes. ${ }^{16}$

Of these 718 study cases, 439 (61.1\%) were male. Tresaet $\mathrm{al}^{9}$ reported $60.3 \%$ male gender predominance. Esezobor $\mathrm{C}$ et $\mathrm{al}^{17}$ from Nigeria also reported $68.6 \%$ male gender predominance in children with $\mathrm{AKI}$. Alkandari $\mathrm{O}$ et $\mathrm{al}^{18}$ from Canada found $53 \%$ male cases. Prodhan $P$ et al ${ }^{19}$ has also found $66 \%$ male cases. Local data from Karachi by Moorani KN et $\mathrm{al}^{20}$ showed $56.6 \%$ male presence among children having AKI.

In this study, mean age of our study cases was $4.33 \pm 2.56$ years while most, $77.2 \%$ cases were aged less than 5 years. Tresaet $\mathrm{al}^{9}$ recorded $7.5 \pm 4.4$ years mean age of the cases with AKI while Esezobor et $\mathrm{al}^{17}$ from Nigeria noted this to be 4.8 years. A study conducted in Canada by Alkandariet $\mathrm{al}^{18}$ reported $5.0 \pm 5.5$ years mean age of the children having AKI. Local data ${ }^{20}$ has revealed 4.7 years mean age which is closer to what we found.

We noted hypertension to be present in $31.8 \%$ cases. Tresa et $\mathrm{al}^{9}$ has reported $37.1 \%$ hypertension in pediatric AKI. Esezoboret $\mathrm{al}^{17}$ has reported $50 \%$ hypertension in children with AKI. Kidney and BP abnormalities are commonly linked with AKI. Other risk factors must be elucidated to develop follow-up recommendations and reduce cardiovascular risk. ${ }^{21}$

\section{CONCLUSION}

Very high frequency of hypertension seen in children presenting with AKI. Hypertension was significantly associated with gender, age, socioeconomic status, family history of hypertension and obesity. All clinicians treating such patients should always screen these children for early diagnosis and timely management of 
hypertension which will protect these children from future adverse events and will improve their quality of life.

Copyright(C) 24 July, 2020.

\section{REFERENCES}

1. Sadeghi-Bojd S, Noori NM, Mohammadi M, Teimouri A. Clinical characteristics and mortality risk prediction in children with acute kidney injury. Niger Med J. 2015; 56(5):327-32.

2. Ximenes RO, Farias $A Q$, Helou $C M$. Early predictors of acute kidney injury in patients with cirrhosis and bacterial infection: urinary neutrophil gelatinaseassociated lipocalin and cardiac output as reliable tools. Kidney ResClinPract. 2015; 34(3):140-5.

3. Olowu WA, Niang A, Osafo C, et al. Outcomes of acute kidney injury in children and adults in Sub-Saharan Africa: A systematic review. Lancet Glob Health 2016; 4:e242-50.

4. Ciccia E, Devarajan P. Pediatric acute kidney injury: Prevalence, impact and management challenges. Int J Nephrol Renovasc Dis. 2017; 10:77-84.

5. Kidney Disease: Improving global outcomes (KDIGO) acute kidney injury working group. KDIGO clinical practice guideline for acute kidney injury. Kidney Int Suppl. 2012; 2(1):1-138.

6. Makris K, Spanou L. Acute kidney injury: Definition, pathophysiology and clinical phenotypes. ClinBiochem Rev. 2016; 37(2):85-98.

7. Ismail HK, Hodan MJ, Li C. A retrospective study of acute renal failure in children: Its incidence, etiology, complications and prognosis. Cureus. 2017; 9(5):e1274.

8. Andreoli SP. Acute kidney injury in children. Pediatr Nephrol. 2009; 24(2): 253-263.

9. Tresa V, Yaseen A, Lanewala AA, Hashmi S, Khatri S, Ali I, et al. Etiology, clinical profile and short-term outcome of acute kidney injury in children at a tertiary care pediatric nephrology center in Pakistan. Ren Fail. 2017; 39(1):26-31.

10. Group KAW. KDIGO clinical practice guideline for acute kidney injury. Kidney Int. 2012; 2:1-138.

11. Sanchez-Pinto LN, Goldstein SL, Schneider JB, Khemani RG. Association between progression and improvement of acute kidney injury and mortality in critically III children. Pediatr Crit Care Med. 2015; 16(8):703-10.
12. Basu RK, Kaddourah A, Terrell T, Mottes T, Arnold P, Jacobs $\mathrm{J}$, et al. Assessment of worldwide acute kidney injury, renal angina and epidemiology in critically ill children (AWARE): Study protocol for a prospective observational study. BMC Nephrol. 2015; 16:24.

13. Lameire N, Van Biesen W, Vanholder R. Epidemiology of acute kidney injury in children worldwide, including developing countries. Pediatr Nephrol. 2017; 32(8):1301-14.

14. Olowu WA, Niang A, Osafo C, Ashuntantang G, Arogundade FA, Porter $\mathrm{J}$, et al. Outcomes of acute kidney injury in children and adults in sub-Saharan Africa: A systematic review. The Lancet Global health. 2016; 4(4):e242-50.

15. Sutherland SM, Ji J, Sheikhi FH, Widen E, Tian L, Alexander SR, et al. AKI in hospitalized children: Epidemiology and clinical associations in a national cohort. Clin J Am SocNephrol. 2013; 8:1661-9.

16. Kwiatkowski DM, Sutherland SM. Acute kidney injury in pediatric patients. Best Practice \& Research Clinical Anaesthesiology 2017; 31(3):427-439.

17. Esezobor Cl, Ladapo TA, Osinaike B, Lesi FE. Paediatric acute kidney injury in a tertiary hospital in Nigeria: Prevalence, causes and mortality rate. PLoS One. 2012; 7(12):e51229.

18. Alkandari O, Eddington KA, Hyder A, Gauvin F, Ducruet $\mathrm{T}$, Gottesman R, et al. Acute kidney injury is an independent risk factor for pediatric intensive care unit mortality, longer length of stay and prolonged mechanical ventilation in critically ill children: A twocenter retrospective cohort study. Crit Care. 2011; 15(3):R146.

19. Prodhan P, McCage LS, Stroud MH, Gossett J, Garcia $X$, Bhutta AT, et al. Acute kidney injury is associated with increased in-hospital mortality in mechanically ventilated children with trauma. J Trauma Acute Care Surg. 2012; 73(4):832-7.

20. Moorani KN, Parkash J, Lal H. Complications of acute peritoneal dialysis in children with acute kidney failure. Pak J Med Res. 2011; 50(2):60-4.

21. Benisty K, Morgan C, Hessey E, Huynh L, Joffe AR, Garros D, et al. Kidney and blood pressure abnormalities 6 years after acute kidney injury in critically ill children: A prospective cohort study. Pediatr Res. 2020 Jan 2. doi: 10.1038/s41390-019-07375. 


\begin{tabular}{|c|l|l|l|}
\hline \multicolumn{3}{|c|}{ AUTHORSHIP } & AND CONTRIBUTION DECLARATION \\
\hline Sr. \# & Author(s) Full Name & \multicolumn{1}{|c|}{ Contribution to the paper } & Author(s) Signature \\
\hline 1 & M Faisal Mehar & $\begin{array}{l}\text { Study concept, Drafting, } \\
\text { Supervision. } \\
\text { Methodology, Data interpretation. }\end{array}$ \\
\hline 3 & Afsheen Asghar Khan & Rushan Hassan & Data analysis. \\
\hline 5 & Madiha Naz & Data collection, Data analysis. \\
\hline 6 & Ali Rehan Nasir & Literature review, Discussion. & \\
\hline
\end{tabular}

